\title{
Preparation of Anti-Aristolochic Acid I Monoclonal Antibody and Development of Chemiluminescent Immunoassay and Carbon Dot-Based Fluoroimmunoassay for Sensitive Detection of Aristolochic Acid I
}

\author{
Ai-Fen Ou ${ }^{1,2}{ }^{,}$Zi-Jian Chen ${ }^{3} \mathbb{D}$, Yi-Feng Zhang ${ }^{3}$, Qi-Yi He ${ }^{1}$, Zhen-Lin $\mathrm{Xu}^{3}{ }^{\mathbb{D}}$ and Su-Qing Zhao ${ }^{1, *}$ \\ 1 Department of Pharmaceutical Engineering, School of Biomedical and Pharmaceutical Sciences, \\ Guangdong University of Technology, Guangzhou 510006, China; ouaifen@gcp.edu.cn (A.-F.O.); \\ chesto36@163.com (Q.-Y.H.) \\ 2 Department of Food, Guangzhou City Polytechnic, Guangzhou 510006, China \\ 3 Guangdong Provincial Key Laboratory of Food Quality and Safety/Guangdong Laboratory of Lingnan \\ Modern Agriculture, South China Agricultural University, Guangzhou 510642, China; \\ guangdongchenzj@163.com (Z.-J.C.); zhyifengscau@163.com (Y.-F.Z.); jallent@163.com (Z.-L.X.) \\ * Correspondence: sqzhao@gdut.edu.cn
}

Citation: Ou, A.-F.; Chen, Z.-J.; Zhang, Y.-F.; He, Q.-Y.; Xu, Z.-L.; Zhao, S.-Q. Preparation of Anti-Aristolochic Acid I Monoclonal Antibody and Development of Chemiluminescent Immunoassay and Carbon Dot-Based Fluoroimmunoassay for Sensitive Detection of Aristolochic Acid I. Foods 2021, 10, 2647. https://doi.org/ $10.3390 /$ foods 10112647

Academic Editor: Thierry Noguer

Received: 27 September 2021

Accepted: 28 October 2021

Published: 1 November 2021

Publisher's Note: MDPI stays neutral with regard to jurisdictional claims in published maps and institutional affiliations.

Copyright: (c) 2021 by the authors. Licensee MDPI, Basel, Switzerland. This article is an open access article distributed under the terms and conditions of the Creative Commons Attribution (CC BY) license (https:// creativecommons.org/licenses/by/ $4.0 /)$
Abstract: Aristolochic acid (AA) toxicity has been shown in humans regarding carcinogenesis, nephrotoxicity, and mutagenicity. Monitoring the AA content in drug homologous and healthy foods is necessary for the health of humans. In this study, a monoclonal antibody (mAb) with high sensitivity for aristolochic acid I (AA-I) was prepared. Based on the obtained $\mathrm{mAb}$, a chemiluminescent immunoassay (CLEIA) against AA-I was developed, which showed the $50 \%$ decrease in the $\mathrm{RLU}_{\max }\left(\mathrm{IC}_{50}\right)$ value of $1.8 \mathrm{ng} / \mathrm{mL}$ and the limit of detection (LOD) of $0.4 \mathrm{ng} / \mathrm{mL}$. Carbon dots with red emission at $620 \mathrm{~nm}$, namely rCDs, were synthesized and employed in conventional indirect competitive enzyme-linked immunosorbent assay (icELISA) to improve the assay sensitivity of a fluoroimmunoassay (FIA). Oxidized 3,3" $, 5,5^{\prime \prime}$-tetramethylbenzidine dihydrochloride (oxTMB) can quench the emission of the rCDs through the inner-filter effect; therefore, the fluorescence intensity of rCDs can be regulated by the concentration of $\mathrm{mAb}$. As a result, the assay sensitivity of FIA was improved by five-fold compared to CLEIA. A good relationship between the results of the proposed assays and the standard ultra-high performance liquid chromatography-triple quadrupole mass spectrometer (UPLC-QQQ-MS/MS) of real samples indicated good accuracy and practicability of CLEIA and FIA.

Keywords: aristolochic acid I; monoclonal antibody; computer-assisted simulation; chemiluminescent immunoassay; fluoroimmunoassay

\section{Introduction}

Aristolochic acids (AAs) are a mixture of structurally related nitrophenanthrene carboxylic acids, mainly consisting of aristolochic acid I (AA-I) and aristolochic acid II (AA-II), which exist in Aristolochia spp. [1,2], a kind of Chinese herb. Moreover, these herbs can be used as raw materials of some drug homologous and healthy foods, and even dietary supplements [3-5]. However, it has been reported that AA showed toxicity to humans owing to carcinogenesis [2,6-8], nephrotoxicity [9-11], and mutagenicity $[9,12]$. Some cases reported that the intake of slimming products containing AA resulted in nephropathy $[13,14]$. Many countries have prohibited products containing AAs. Therefore, it is necessary to develop effective methods for detecting and monitoring AA in related food products.

For the analysis of AA, the main detection method is the conventional instrumental method, high performance liquid chromatography (HPLC) [15-17], due to the high 
accuracy and high reproducibility. Nevertheless, it is a challenge that the instrumental method is limited by high cost, the need for professional operators, and a long turnaround time. Therefore, immunoassay was proposed in this study because of the advantages of rapidness, high-throughput, sensitivity, low-cost, simple pretreatment requirement. It is easy-to-use and has been widely applied in fields of food analysis [18-24].

The most common and mature detection technology for the immunoassay of AAs is conventional indirect competitive enzyme-linked immunosorbent assay (icELISA); however, the sensitivity of icELISA cannot meet the needs of strict screening. In this study, a chemiluminescent immunoassay (CLEIA) was developed concerning its higher sensitivity compared with conventional icELISAs [25,26]. On the other hand, a fluoroimmunoassay (FIA) is a potential methodology through its advantages, including high sensitivity, real-time, fast response, and low cost to improve the method sensitivity [27]. As a novel fluorescent probe, the carbon dots (CDs) exhibit superiority of remarkable fluorescent properties, simple preparation, good biocompatibility, and easy functionalization [28], which can be employed for FIA. For FIA development, most previous publications reported a phosphate-triggered method to recover the fluorescence of CDs [29-31]. Nevertheless, alkaline phosphatase (ALP) activity requires more than $30 \mathrm{~min}$ for the catalyst, which is not satisfactory. For overcoming this time-consuming step, we employed horseradish peroxidase (HRP) and developed red CDs (rCDs)-based FIA. Compared with ALP, the activity of HRP is higher and its catalysate-oxidized $3,3^{\prime \prime}, 5,5^{\prime \prime}$-tetramethylbenzidine dihydrochloride (oxTMB) can quench rCDs. Based on the above principle, we developed HRP and rCDs based on FIA for AAs analysis.

\section{Materials and Methods}

\subsection{Reagents and Animals}

Standards of AA-I, AA-II, AA-III, AA-IV, and its analogs were purchased from Yuanye Co. Ltd. (Shanghai, China). Citric acid, urea, N,N-dimethylformamide (DMF), 1-(3dimethylaminopropyl)-3-ethylcarbodiimide hydrochloride (EDC), N-hydroxysuccinimide (NHS) were supplied by Heowns Chemical Technology Co., Ltd. (Tianjin, China). The ovalbumin (OVA), keyhole limpet haemocyanin (KLH), and bovine serum albumin (BSA) were supplied by Sigma (Shanghai, China). The incomplete and complete Freund's adjuvants were purchased from Merck Co. Ltd. (Shanghai, China). The TMB and chemiluminescent substrate solution were obtained from Yuanye Co. Ltd. (Shanghai, China). Protein G resin and a secondary antibody (goat anti-mouse IgG, HRP conjugated) were obtained from TransGen Biotech Co. Ltd. (Beijing, China).

$\mathrm{Bal} \mathrm{b} / \mathrm{c}$ female mice were purchased from the Guangdong Medical Experimental Animal Centre and raised at the Animal Experiment Centre of South China Agriculture University (Animal Experiment Ethical Approval Number: 2019054, Figure S1).

\subsection{Instruments}

Multiskan FC microplate reader (Thermo Fisher, Shanghai, China) was used to measure absorbance values. The fluorescence was measured at emission (Em) wavelengths of $620 \mathrm{~nm}$ with excitation (Ex) wavelength of $540 \mathrm{~nm}$ using a SpectraMax i3 microplate reader (Molecular Devices, USA). A NanoDrop2000c spectrophotometer (Thermo Fisher, Shanghai, China) was used for concentration measurement and UV spectrum characterization.

\subsection{Production of Monoclonal Antibody}

Since AA-I is the main compound of AAs, it was directly conjugated to a carrier protein to prepare immunogen and coating antigen. The conjugation procedure was referred to in our previous study [32], and the details are summarized in Supporting Information. The artificial antigens were characterized by ultraviolet visible (UV-vis) spectral. The molar ratio between hapten and carrier protein was obtained by MALDI-TOF-MS. 
The produced artificial antigens were used for animal immunization described in our previous study [32]. The production of $\mathrm{mAb}$ was followed by our previous publication [33]. The obtained $\mathrm{mAb}$ was purified by protein $\mathrm{G}$ and stored at $-20^{\circ} \mathrm{C}$.

\subsection{Development of Chemiluminescent Immunoassay}

A serial concentration of AA-I $(50 \mu \mathrm{L})$ and $50 \mu \mathrm{L}$ of mAb solution was added to each well for $40 \mathrm{~min}$ incubation at $37^{\circ} \mathrm{C}$. Afterward, HRP-conjugated secondary antibody was added $(100 \mu \mathrm{L} /$ well) after five times washing with PBST (PBS with $0.5 \%$ Tween-20) for $30 \mathrm{~min}$ incubation at $37^{\circ} \mathrm{C}$. Then the chemiluminescent substrate solution was added $(100 \mu \mathrm{L} /$ well), and the RLU value was measured after a 1 min reaction. The calibration curve was fitted by sigmoidal fitting using the percent binding of $\mathrm{mAb}$ in the wells (RLU/RLU ${ }_{0}$ ) against the logarithm of the AA-I concentration. The $50 \%$ decrease in the $\mathrm{RLU}_{\max }\left(\mathrm{IC}_{50}\right)$ value was calculated using Origin 8.5. The optimal conditions were confirmed from the $\mathrm{IC}_{50}$ value, including the optimal $\mathrm{pH}$, coating antigen/antibody, phosphate, and Tween-20 concentration.

\subsection{Development of Fluoroimmunoassay}

The synthesis of rCDs is summarized in Supporting Information for the development of FIA. It was the same as CLEIA except using TMB as substrate and polystyrene transparent microplate. After oxTMB generation, the solution of each well was mixed with $50 \mu \mathrm{L}$ of $\mathrm{NaOH}(1 \mathrm{mM}, \mathrm{pH} 11)$ to adjust the $\mathrm{pH}$. Then, $\mathrm{rCDs}(50 \mu \mathrm{L})$ were added and mixed quickly. One hundred microliters of the mixture were transferred to black polystyrene opaque microplate, and the fluorescence signal was measured with Ex $540 \mathrm{~nm}$ and Em $620 \mathrm{~nm}$.

\subsection{Recovery Test}

Samples (drug homologous and foods) were obtained from a supermarket in Guangzhou city. Samples $(600,300$, and $150 \mathrm{ng} / \mathrm{g}$ ) were ground into a powder using a stainlesssteel grinder. The AA-I was added to samples $(5.0 \mathrm{~g})$ and mixed with methanol $(5 \mathrm{~mL})$ for 30 min ultrasonic water bath treatment. Afterward, the mixture was centrifuged at $4000 \mathrm{rpm}(2057 \times g)$ for $10 \mathrm{~min}$. The extraction solution was dried by nitrogen flow and redissolved in an equivalent volume of $0.01 \mathrm{M} \mathrm{pH} 5.4 \mathrm{PBS}$ (PB with $75 \mathrm{mM} \mathrm{NaCl}$ ) and employed for CLEIA and FIA. For UPLC-QQQ-MS/MS, the redissolved solutions were filtered by $0.22 \mu \mathrm{m}$ cellulose membrane before analysis. The details of UPLC-QQQ-MS/MS are summarized in Table S1.

\section{Results}

\subsection{Characterization of Antisera}

In this study, AA-I was conjugated to a carrier protein directly. The ultraviolet scanning showed that the synthesized artificial antigens exhibited the characteristic absorption peak of AA-I and carrier proteins, suggesting the successful preparation of artificial antigens (Figure S2). The prepared immunogen and coating antigen were further utilized to prepare anti-AA-I mAb. The strategy is shown in Figure 1. The mouse antisera characterization is summarized in Table 1 . The highest titer and sensitivity were observed for mouse 4 using AA-I-KLH, which was chosen for the production of $\mathrm{mAb}$. After subclone and hybridoma screening, the most sensitive cell lines $3 \mathrm{~A} 3$ were obtained and used for ascites preparation (Table S2). Finally, the mAb was obtained after ascites purification and was stored at $-20^{\circ} \mathrm{C}$ after concentration measurement by Nanodrop. 
<smiles>COc1cccc2c1cc(C(=O)[O-])c1c3c(cc(C(=O)O)c12)OCO3</smiles>

AA-I

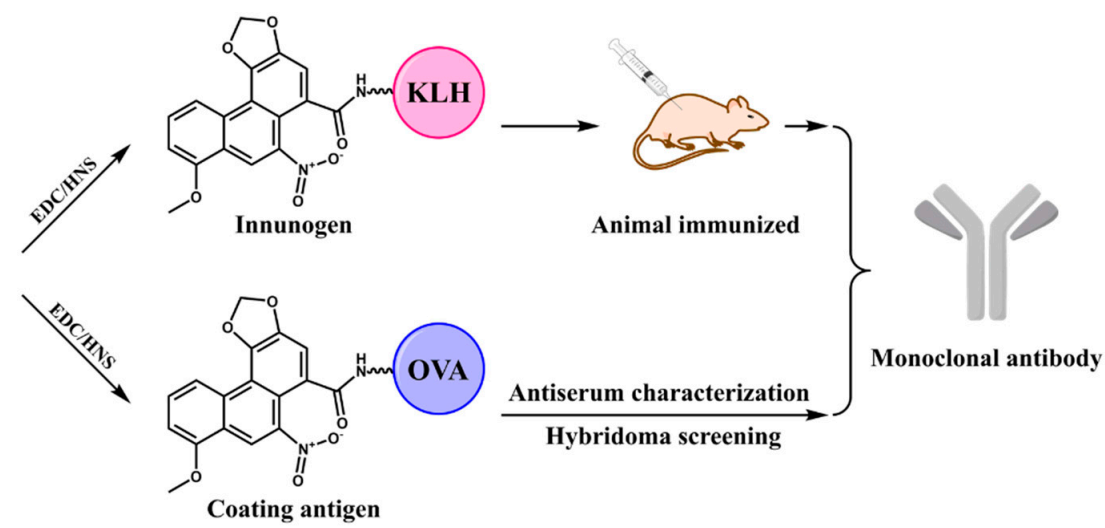

Figure 1. The strategic schema of mAb production. AA-I: aristolochic acid I; EDC: 1-(3dimethylaminopropyl)-3-ethylcarbodiimide hydrochloride; NHS: N-hydroxysuccinimide; KLH: keyhole limpet haemocyanin; OVA: ovalbumin.

Table 1. Characterization of mouse antiserum against AA-I $(n=3)$.

\begin{tabular}{ccccc}
\hline Mouse & Immunogen & Coating Antigen $^{\mathbf{1}}$ & Titer & IC $_{\mathbf{5 0}}(\mathbf{n g} / \mathbf{m L})$ \\
\hline 1 & AA-I-BSA & AA-I-OVA & $16 \mathrm{~K}$ & $120.3 \pm 13.0$ \\
2 & AA-I-BSA & AA-I-OVA & $32 \mathrm{~K}$ & $148.8 \pm 11.8$ \\
3 & AA-I-BSA & AA-I-OVA & $16 \mathrm{~K}$ & $156.1 \pm 16.2$ \\
4 & AA-I-KLH & AA-I-OVA & $64 \mathrm{~K}$ & $27.3 \pm 4.3$ \\
5 & AA-I-KLH & AA-I-OVA & $64 \mathrm{~K}$ & $56.6 \pm 7.7$ \\
6 & AA-I-KLH & AA-I-OVA & $32 \mathrm{~K}$ & $35.8 \pm 3.6$ \\
\hline
\end{tabular}

${ }^{1}$ The concentration of coating antigen was $1 \mu \mathrm{g} / \mathrm{mL}$.

\subsection{Development of CLEIA}

After condition optimization, the CLEIA was further developed. The highest sensitivity was achieved with the coating concentration of $2 \mu \mathrm{g} / \mathrm{mL}$ and antibody concentration of $250 \mathrm{ng} / \mathrm{mL}$ (Table S3). For the working buffer, the optimized solution was $\mathrm{pH} 5.4$ PBS with a concentration of $0.01 \mathrm{M}$ (Figure S3). Finally, calibration curves against AA-I were developed and showed the $\mathrm{IC}_{50}$ of $2.4 \mathrm{ng} / \mathrm{mL}$ with a linear range $\left(\mathrm{IC}_{20}-\mathrm{IC}_{80}\right)$ from 0.2 to $3.1 \mathrm{ng} / \mathrm{mL}$ (Figure 2). The $\mathrm{IC}_{10}\left(10 \%\right.$ decrease in the $\left.\mathrm{RLU}_{\max }\right)$ was defined as the limit of detection (LOD), $0.4 \mathrm{ng} / \mathrm{mL}$.
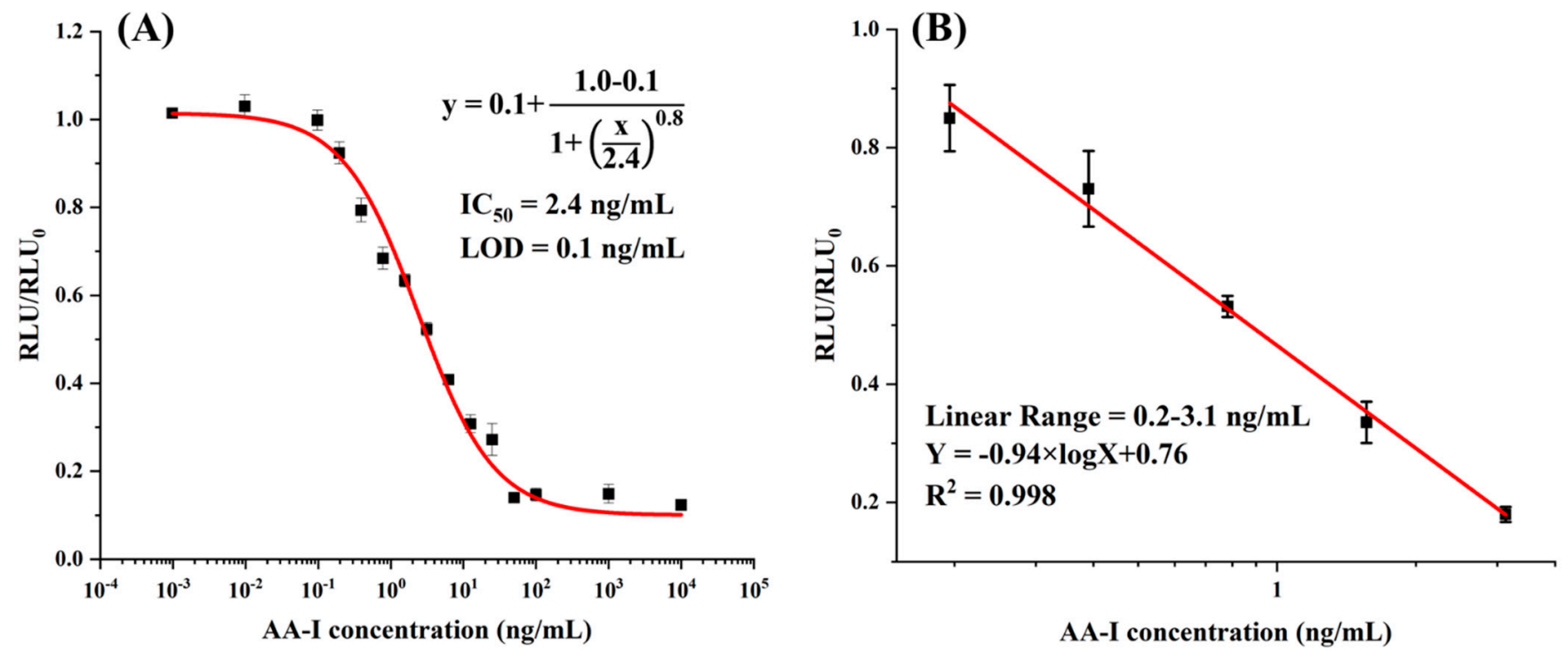

Figure 2. (A) The calibration curve; (B) the linear range of CLEIA. 
Based on the developed CLEIA, the specific test for mAb was performed, and the results are summarized in Table 2. To be noticed, the AA-II showed the highest crossreactivity $(\mathrm{CR})$ amount of these analogs while only slight CR was observed for AA-III and AA-IV, suggesting the hydroxyl was the key site for recognition. For the other analogs, no obvious CR was observed, indicating the good specificity of mAb to AAs. Since both AA-I and AA-II were the main components in the samples, the obtained mAb can be used for screening these two AAs.

Table 2. The specific test of anti-AA-I mAb.

Ephedrine hydrochloride

${ }^{1} \mathrm{CR}(\%)=\left[\mathrm{IC}_{50}(\mathrm{AA}-\mathrm{I}) / \mathrm{IC}_{50}\right.$ (analogues) $] \times 100 \%$.

\subsection{Characterization of $r C D s$}

The rCDs were synthesized and characterized for the development of FIA. As shown in Figure 3A, rCDs exhibited a particle size of approximately $3 \mathrm{~nm}$. Moreover, the highresolution TEM image clearly showed the lattice fringe of rCDs with an interlayer spacing of $0.21 \mathrm{~nm}$ (Figure 3A). The dynamic light scattering (Figure 3B) showed the hydrodynamic size of $\sim 2.7 \mathrm{~nm}$ for rCDs, which agreed with TEM. 

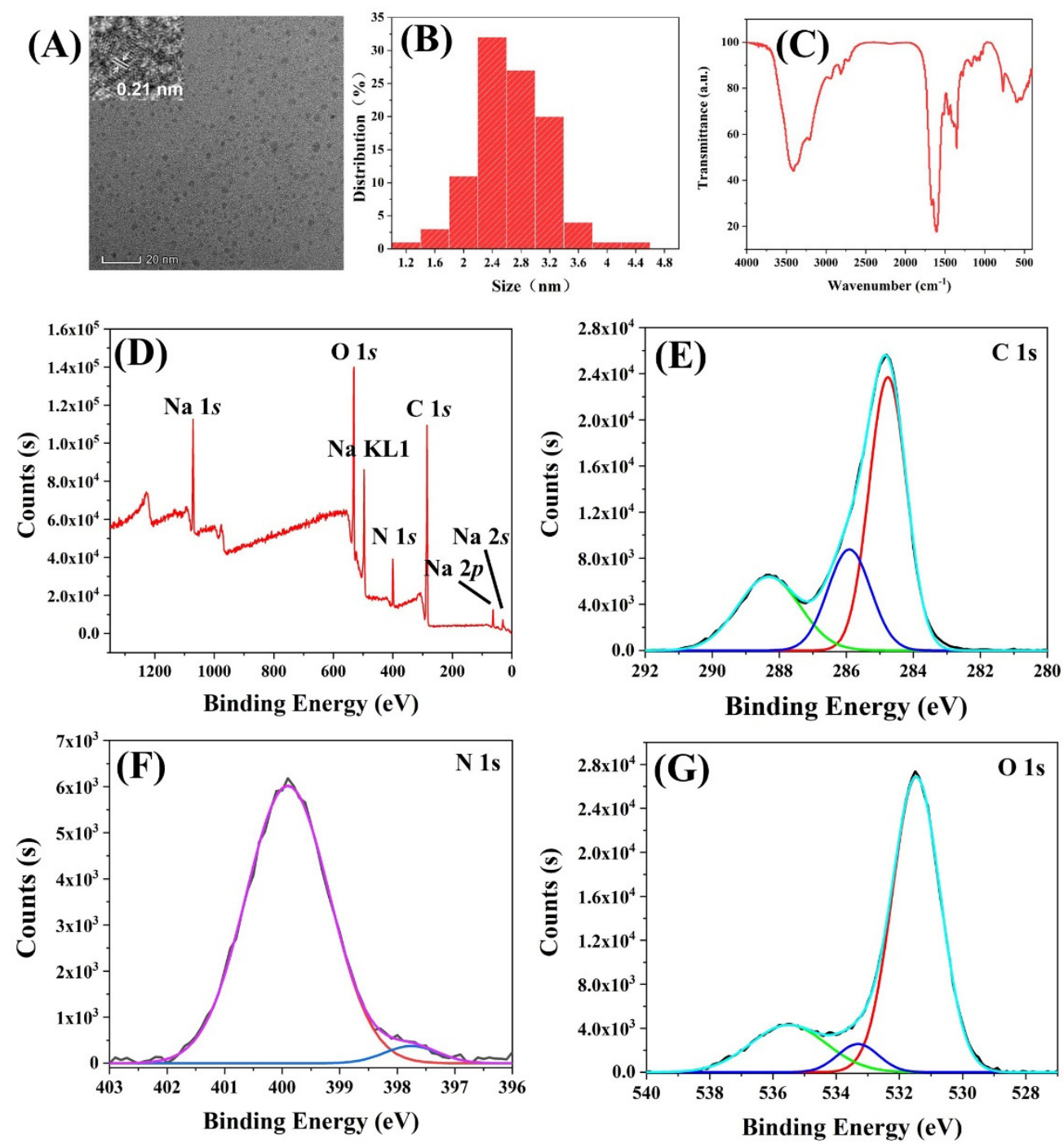

Figure 3. Characterization of rCDs; (A) the transmission electron microscope image; (B) the hydrodynamic size; (C) FTIR image; (D) survey XPS spectrum and high resolution of (E) C 1s, (F) N 1s, and (G) $\mathrm{O} 1 \mathrm{~s}$.

The Fourier transform infrared (FTIR) was employed to characterize the functional group of rCDs (Figure 3C). A wide peak from 3100 to $3500 \mathrm{~cm}^{-1}$ was found from the FTIR image, which was assigned to the stretching vibrations of the $\mathrm{O}-\mathrm{H}$ or $\mathrm{N}-\mathrm{H}$ group, while those from 2800 to $3000 \mathrm{~cm}^{-1}$ could be attributed to the stretching vibrations of $\mathrm{C}-\mathrm{H}$. The peaks at 1610,1510, and $1450 \mathrm{~cm}^{-1}$ indicated the generation of the aromatic group. The stretching vibrations of $\mathrm{C}=\mathrm{O}$ or $\mathrm{C}=\mathrm{N}$ can be verified from the peak of $1680 \mathrm{~cm}^{-1}$, and the peak at $1350 \mathrm{~cm}^{-1}$ was caused by the stretching vibrations of $\mathrm{C}-\mathrm{N}$, which demonstrated the generation of amide or carboxyl. The peak at 1000-1270 $\mathrm{cm}^{-1}$ was originated from stretching vibrations of $\mathrm{C}-\mathrm{O}$, implying the existence of ether group or hydroxyl. Furthermore, the peak at $764 \mathrm{~cm}^{-1}$ was ascribed to the out-of-plane bending vibration of $\mathrm{O}-\mathrm{H}$ or $\mathrm{C}-\mathrm{H}$ demonstrated the ring-shaped conjugated structures in rCDs.

To verify the inference described above, the survey X-ray photoelectron spectroscopy (XPS) was employed. Figure 3D clearly shows the binding energy peaks of $\mathrm{C} 1 \mathrm{~s}, \mathrm{~N} 1 \mathrm{~s}$, and $\mathrm{O} 1 \mathrm{~s}$, while the peaks of sodium of $\mathrm{Na} 1 \mathrm{~s}, \mathrm{Na} 2 \mathrm{~s}, \mathrm{Na} 2 \mathrm{p}$, and Na KL1 were ascribed to the addition of $\mathrm{NaOH}$ in the synthesis of rCDs. The high-resolution XPS showed the three peaks of $C 1$ s (Figure 3E), corresponding to $284.8 \mathrm{eV}(\mathrm{C}=\mathrm{C} / \mathrm{C}-\mathrm{C}), 285.9 \mathrm{eV}(\mathrm{C}-\mathrm{N} / \mathrm{C}-\mathrm{O} / \mathrm{C}=\mathrm{N})$, and $288.3 \mathrm{eV}(\mathrm{O}=\mathrm{C}-\mathrm{O})$. Two fitting peaks of $\mathrm{N} 1 \mathrm{~s}$ at $399.9 \mathrm{eV}$ and $397.7 \mathrm{eV}$ were attributed to the pyridinic $\mathrm{N}$ and pyrrolic $\mathrm{N}$, respectively (Figure $3 \mathrm{~F}$ ). Figure $3 \mathrm{G}$ confirms the presence 
of $\mathrm{C}=\mathrm{O}(531.5 \mathrm{eV})$ bonds, $\mathrm{O}=\mathrm{C}-\mathrm{O}$ group $(533.5 \mathrm{eV})$, and the $\mathrm{C}-\mathrm{O}$ of the aromatic nucleus $(535.5 \mathrm{eV})$. In general, the results of XPS showed good agreement with the generation of the aromatic group from FTIR analysis.

\subsection{Development of FIA}

The spectral characteristic of $\mathrm{rCDs}, \mathrm{TMB}$, and oxTMB was investigated to assess the feasibility of FIA development. Figure $4 \mathrm{~A}$ shows the Em wavelength of rCDs at $620 \mathrm{~nm}$ with the Ex wavelength at $540 \mathrm{~nm}$. Compared with TMB, the oxTMB exhibited an obvious absorbance peak at $650 \mathrm{~nm}$, which overlaps the Em of rCDs, thereby quenching the fluorescent signal of rCDs. Therefore, the presence of HRP can catalyze TMB into oxTMB to quench rCDs; otherwise, the fluorescent signal was a turn-on. The fluorescence lifetime of $\mathrm{rCDs}$ was investigated. In the presence of oxTMB, the fluorescence lifetime of rCDs (5.57 ns) showed no obvious difference to rCDs without oxTMB (5.59 ns), indicating the inner-filter effect caused the quenching (Figure 4B). The fluorescent intensity of rCDs with various $\mathrm{pH}$ values was also studied, and the highest intensity was observed for the $\mathrm{pH}$ value of 11 (Figure S4). Therefore, $\mathrm{rCDs}$ were diluted by $\mathrm{NaOH}$ (pH 11) to adjust the $\mathrm{pH}$ value before adding to microplates.

Based on the quenching mechanism, an rCDs-based FIA was developed, strategy diagram is shown in Figure $4 \mathrm{C}$. In the absence of AA-I, the mAb was bound to coating antigen, resulting in the generation of oxTMB, leading to the quenching of rCDs. In contrast, the presence of AA-I inhibited the binding of $\mathrm{mAb}$ to coating antigen, recovering the fluorescent signal of rCDs. Hence AA-I concentration regulated the fluorescence response. Based on the above optimized conditions, a fluorescent calibration curve against AA-I showed the $\mathrm{IC}_{50}$ of $0.41 \mathrm{ng} / \mathrm{mL}$ (Figure $4 \mathrm{D}$ ), the LOD of $0.06 \mathrm{ng} / \mathrm{mL}$, and a linear range from 0.08 to $2.5 \mathrm{ng} / \mathrm{mL}$. Compared with other publications for AA-I analysis, the developed FIA showed higher sensitivity (LOD) (Table 3), simplicity, and high efficiency without a complicated procedure for sensitivity improvement, which makes the FIA suitable for sample screening. The downsides are that the FIA still requires at least approximately 90 min to detect AA-I, and the microplate reader requirement limits the on-site detection of FIA. To overcome these shortcomings, handheld reader-based lateral flow immunoassays will be developed in future work for more rapid and on-site detection of AA-I.

Table 3. The comparison of immunoassay for AAs.

\begin{tabular}{ccccc}
\hline Method & IC $_{\mathbf{5 0}}(\mathbf{n g} / \mathbf{m L})$ & Linear Range $(\mathbf{n g} / \mathbf{m L})$ & LOD $(\mathbf{n g} / \mathbf{m L})$ & Reference \\
\hline icELISA & 1.2 & ND $^{1}$ & 0.1 & 3 \\
Injection analysis chemiluminescence & $\mathrm{ND}^{1}$ & $10-20000$ & 4 & This work \\
CLEIA & 2.4 & $0.2-3.1$ & 0.1 & This work \\
FIA & 0.41 & $0.08-2.50$ & 0.06 & \\
\hline
\end{tabular}

${ }^{1} \mathrm{ND}$, no data.

\subsection{Recovery Test}

Three levels of AA-I were spiked to drug homologous and foods then analyzed by CLEIA and FIA. The results were verified by UPLC-QQQ-MS/MS, which is shown in Table 4 . The recoveries of CLEIA and FIA were ranged between $83-119 \%$ and $86-118.4 \%$ with a coefficient of variance $(\mathrm{CV})$ ranging from $3.8 \%$ to $13.3 \%$ and $5 \%$ to $14.4 \%$, respectively. The UPLC-QQQ-MS/MS showed the average recoveries from $85.1 \%$ to $108.1 \%$, with CVs from $1.2 \%$ to $7.5 \%$. The developed CLEIA and FIA showed good agreement to standard instrument methods, demonstrating good accuracy and practicability for AA-I detection. 
(A)

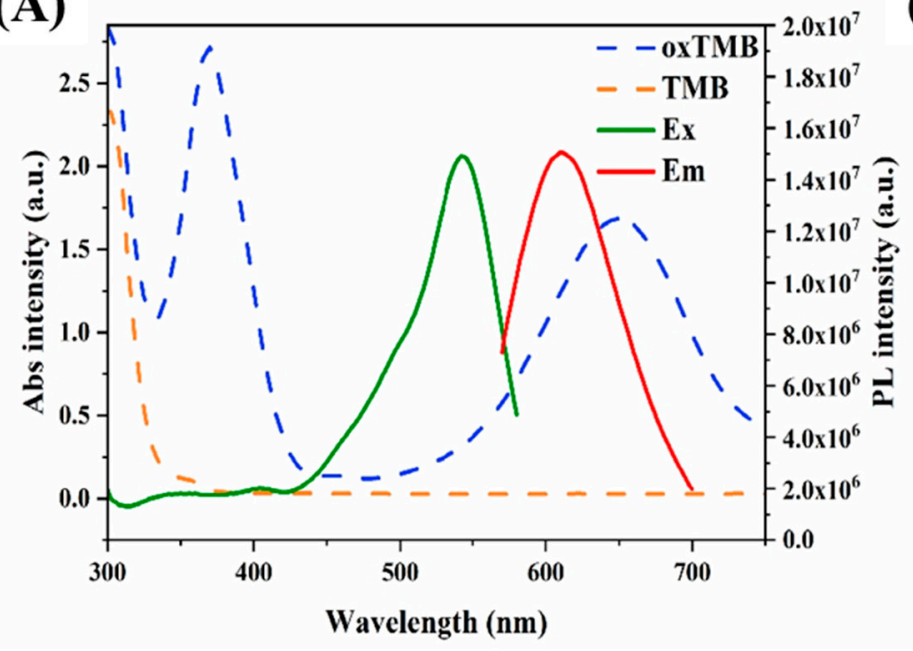

(B)

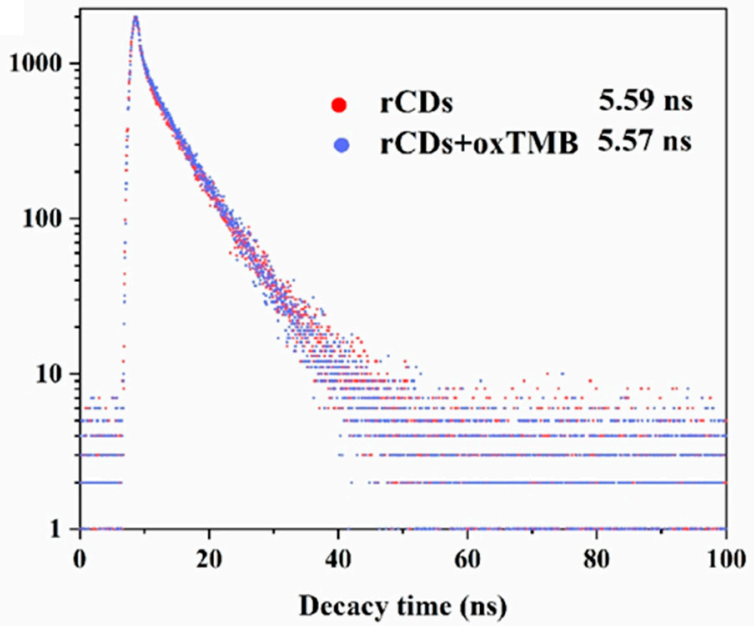

(C)

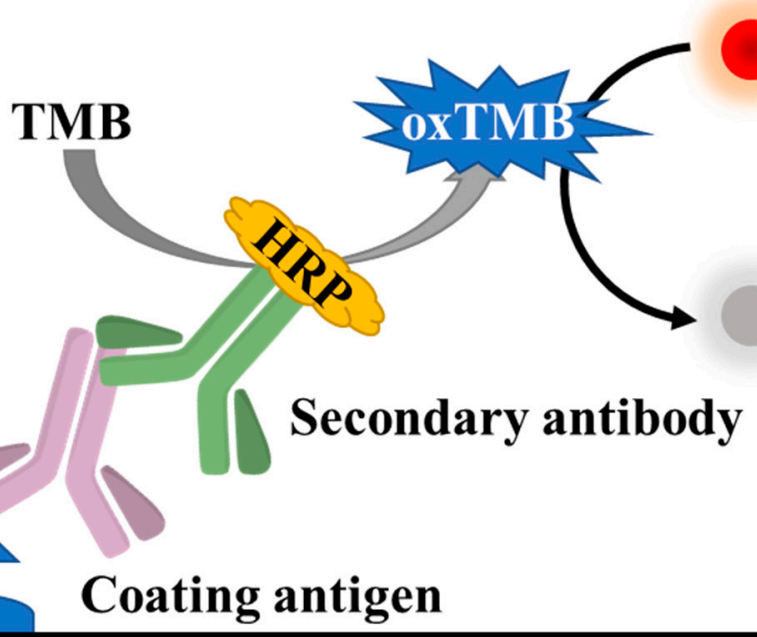

(D)

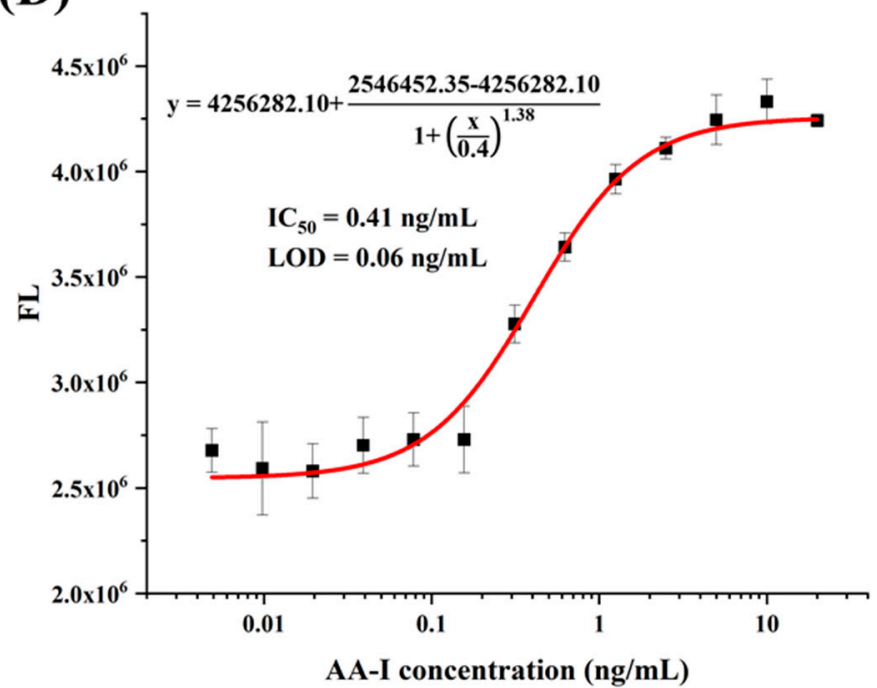

(E)

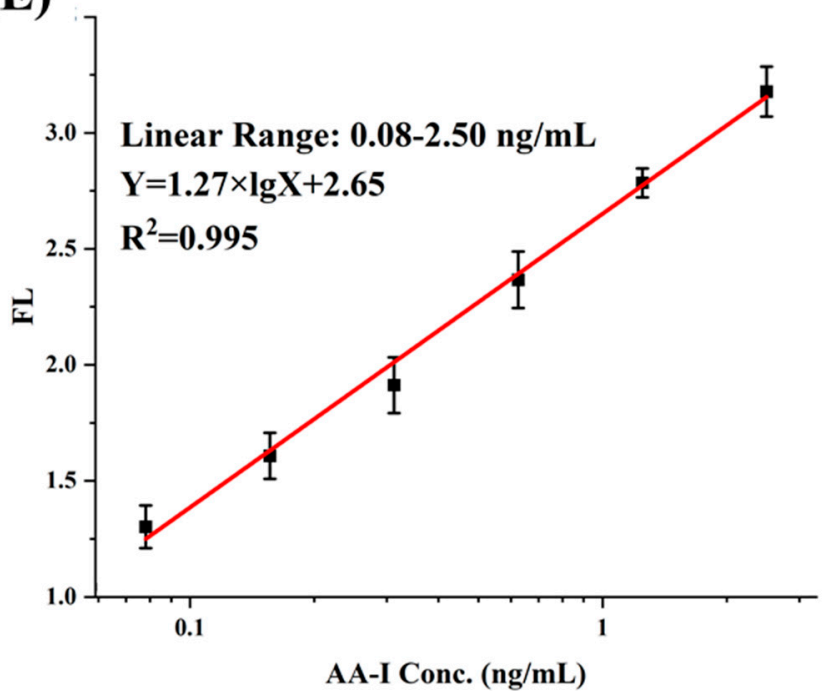

Figure 4. (A) The spectrum characterization of rCDs, TMB, and oxTMB. (B) The lifetime analysis of rCDs with and without oxTMB. (C) Strategic schema of development of FIA. (D) Calibration curve and (E) linear range of FIA. Acronym: TMB: $3,3^{\prime \prime}, 5,5^{\prime \prime}$-tetramethylbenzidine dihydrochloride; oxTMB: oxidized TMB; Em: emission; Ex: excitation. 
Table 4. Recovery test for CLEIA, FIA, and UPLC-QQQ-MS/MS $(n=3)$.

\begin{tabular}{|c|c|c|c|c|c|c|c|c|c|c|}
\hline \multirow[b]{2}{*}{$\begin{array}{c}\text { Sample } \\
\text { No. }\end{array}$} & \multirow[b]{2}{*}{$\begin{array}{c}\text { Spiked } \\
\text { (ng/g) }\end{array}$} & \multicolumn{3}{|c|}{ CLEIA } & \multicolumn{3}{|c|}{ FIA } & \multicolumn{3}{|c|}{ UPLC-QQQ-MS/MS } \\
\hline & & $\begin{array}{c}\text { Measured } \\
(\mathrm{ng} / \mathrm{mL}) \\
\left(\text { Mean } \pm \mathrm{SD}^{1}\right)\end{array}$ & $\begin{array}{c}\text { Recovery } \\
(\%)\end{array}$ & $\begin{array}{l}\mathrm{CV}^{2} \\
(\%)\end{array}$ & $\begin{array}{c}\text { Measured } \\
(\mathrm{ng} / \mathrm{mL}) \\
(\text { Mean } \pm \mathrm{SD})\end{array}$ & $\begin{array}{c}\text { Recovery } \\
(\%)\end{array}$ & $\begin{array}{l}\text { CV } \\
(\%)\end{array}$ & $\begin{array}{c}\text { Measured } \\
(\mathrm{ng} / \mathrm{mL}) \\
(\text { Mean } \pm \mathrm{SD})\end{array}$ & $\begin{array}{c}\text { Recovery } \\
(\%)\end{array}$ & $\begin{array}{l}\mathrm{CV} \\
(\%)\end{array}$ \\
\hline \multirow{3}{*}{$\begin{array}{l}\text { Pleurotus } \\
\text { ostreatus }\end{array}$} & 600 & $511.4 \pm 41.4$ & 86.7 & 7.7 & $655.2 \pm 92.4$ & 109.2 & 14.1 & $648.3 \pm 11.9$ & 108.1 & 1.8 \\
\hline & 300 & $165.3 \pm 21.9$ & 83.0 & 13.3 & $355.2 \pm 55.2$ & 118.4 & 15.5 & $303.7 \pm 12.9$ & 101.2 & 4.2 \\
\hline & 150 & $135.1 \pm 14$ & 90.0 & 12.8 & $129 \pm 18$ & 86 & 14.0 & $127.7 \pm 9.6$ & 85.1 & 7.5 \\
\hline \multirow{3}{*}{$\begin{array}{l}\text { Slimming } \\
\text { capsule }\end{array}$} & 600 & $520.1 \pm 11.3$ & 86.7 & 10.4 & $642 \pm 92.4$ & 107 & 14.4 & $571.3 \pm 12.9$ & 95.2 & 2.3 \\
\hline & 300 & $237.9 \pm 30.4$ & 119.0 & 12.6 & $306 \pm 28.8$ & 102 & 9.4 & $313.7 \pm 16.5$ & 104.6 & 5.3 \\
\hline & 150 & $116 \pm 41.1$ & 116.0 & 36.2 & $147 \pm 21$ & 98 & 14.3 & $136 \pm 5.6$ & 90.7 & 4.1 \\
\hline \multirow{3}{*}{$\begin{array}{l}\text { Slimming } \\
\text { tea }\end{array}$} & 600 & $517.4 \pm 11.8$ & 86.7 & 3.8 & $678 \pm 62.4$ & 113 & 9.2 & $644.3 \pm 7.5$ & 107.4 & 1.2 \\
\hline & 300 & $204.9 \pm 45.7$ & 102.0 & 22.5 & $312 \pm 15.6$ & 104 & 5.0 & $305.3 \pm 11.9$ & 101.8 & 3.9 \\
\hline & 150 & $114.3 \pm 13.3$ & 114.0 & 12.3 & $138 \pm 9$ & 92 & 6.5 & $155.3 \pm 6.5$ & 103.5 & 4.2 \\
\hline
\end{tabular}

${ }^{1} \mathrm{SD}$, standard deviation; ${ }^{2} \mathrm{CV}$, coefficient of variance.

\section{Conclusions}

In this study, the AA-I was conjugated to a carrier protein to prepare artificial antigen, and a sensitive anti-AA-I mAb was generated after animal immunization and hybridoma screening. The obtained $\mathrm{mAb}$ was further used to develop CLEIA for the detection of AA-I. Since products containing AAs are prohibited in most countries, high sensitivity methods are needed to screen out positive samples, but the sensitivity of CLEIA was still not satisfying. Therefore, CDs with red emission were synthesized and employed to develop FIA, which exhibited a five-fold improvement in sensitivity than CLEIA. The accuracy and practicability of CLEIA and FIA were verified by the standard instrument method; they were sensitive, rapid, and easy to use, making them effective tools for screening AA-I in related products.

Supplementary Materials: The following are available online at https://www.mdpi.com/article/10 .3390 / foods10112647/s1. Figure S1: Ethical review of animal experiments. Figure S2: Ultraviolet scanning of synthesized antigens of AA-I (A) Ultraviolet spectrum of AA-I, KLH and AA-I-KLH; (B) AA-I, BSA and AA-I-BSA; (C) AA-I, OVA and AA-I-OVA. Figure S3: The optimizing of $(\mathrm{A}, \mathrm{B})$ ionic strength; $(C, D)$ pH value; $(E, F)$ Tween-20 concentration; $(G, H)$ methanol concentration. Figure S4: The optimizing of $\mathrm{pH}$ for rCDs. Table S1: Parameters of UPLC-QQQ-MS/MS. Table S2: Cell lines evaluation $(n=3)$. Table S3: Optimization of coating antigen concentration $(n=3)$.

Author Contributions: Conceptualization, methodology, software, and writing-original draft preparation, A.-F.O.; methodology and software, Z.-J.C.; methodology, Y.-F.Z.; methodology, Q.-Y.H.; conceptualization, Z.-L.X.; conceptualization, writing-reviewing and editing, S.-Q.Z. All authors have read and agreed to the published version of the manuscript.

Funding: Please add: This research was funded by Guangzhou Science and Technology Foundation, grant number 201903010034; Natural Resources Science Foundation of Guangdong Province, grant number 2018A030313926; Science and Technology Foundation Key R\&D Program of Guangdong Province, grant number 2019B020209009 \& 2019B020218009; R\&D Program of Guangdong Province Drug Administration grant number 2021 TDZ09 \& 2021YDZ06.

Institutional Review Board Statement: The animal experiment was carried out in a laboratory with a license for experiment animal, which was conformed to the welfare principle (ethical approval number: 2019054, Figure S1).

Informed Consent Statement: Not applicable.

Data Availability Statement: The datasets used and analyzed during the current study are available from the corresponding author on request.

Conflicts of Interest: The authors declare no conflict of interest. 


\section{References}

1. Yu, F.Y.; Lin, Y.H.; Su, C.C. A sensitive enzyme-linked immunosorbent assay for detecting carcinogenic aristolochic acid in herbal remedies. J. Agric. Food Chem. 2006, 54, 2496-2501. [CrossRef] [PubMed]

2. Yeh, Y.H.; Lee, Y.T.; Hsieh, H.S.; Hwang, D.F. Short-term toxicity of aristolochic acid, aristolochic acid-I and aristolochic acid-II in rats. Food Chem. Toxicol. 2008, 46, 1157-1163. [CrossRef] [PubMed]

3. Lee, T.Y.; Wu, M.L.; Deng, J.F.; Hwang, D.F. High-performance liquid chromatographic determination for aristolochic acid in medicinal plants and slimming products. J. Chromatogr. B 2002, 766, 169-174. [CrossRef]

4. Oraby, H.F.; Alarfaj, N.A.; El-Tohamy, M.F. Gold nanoparticle-enhanced luminol/ferricyanide chemiluminescence system for aristolochic acid-I detection in medicinal plants and slimming products. Green Chem. Lett. Rev. 2017, 10, 138-147. [CrossRef]

5. Ioset, J.R.; Raoelison, G.E.; Hostettmann, K. Detection of aristolochic acid in Chinese phytomedicines and dietary supplements used as slimming regimens. Food Chem. Toxicol. 2003, 41, 29-36. [CrossRef]

6. Nault, J.; Letouzé, E. Mutational processes in hepatocellular carcinoma: The story of aristolochic acid. Semin. Liver Dis. 2019, 39, 334-340. [CrossRef]

7. Nortier, J.L.; Martinez, M.M.; Schmeiser, H.H.; Arlt, V.M.; Bieler, C.A.; Petein, M.; Depierreux, M.F.; De Pauw, L.; Abramowicz, D.; Vereerstraeten, P.; et al. Urothelial carcinoma associated with the use of a Chinese herb (Aristolochia fangchi). N. Engl. J. Med. 2000, 342, 1686-1692. [CrossRef]

8. Cosyns, J.; Jadoul, M.; Squifflet, J.; van Cangh, P.; van Ypersele de Strihou, C. Urothelial malignancy in nephropathy due to Chinese herbs. Lancet 1994, 344, 188. [CrossRef]

9. Zhang, H.M.; Zhao, X.H.; Sun, Z.H.; Li, G.C.; Liu, G.C.; Sun, L.R.; Hou, J.Q.; Zhou, W. Recognition of the toxicity of aristolochic acid. J. Clin. Pharm. Ther. 2019, 44, 157-162. [CrossRef]

10. Jadot, I.; Declèves, A.; Nortier, J.; Caron, N. An integrated view of aristolochic acid nephropathy: Update of the literature. Int. J. Mol. Sci. 2017, 18, 297. [CrossRef]

11. Kocic, G.; Gajic, M.; Tomovic, K.; Hadzi Djokic, J.; Anderluh, M.; Smelcerovic, A. Purine adducts as a presumable missing link for aristolochic acid nephropathy-related cellular energy crisis, potential anti-fibrotic prevention and treatment. Brit. J. Pharmacol. 2021, 178, 4411-4427.

12. Koyama, N.; Yonezawa, Y.; Nakamura, M.; Sanada, H. Evaluation for a mutagenicity of aristolochic acid by Pig-a and PIGRET assays in rats. Mutat. Res. Genet. Toxicol. Environ. Mutagen. Environ. Mutagenesis 2016, 811, 80-85. [CrossRef]

13. Vanherweghem, J.; Tielemans, C.; Abramowicz, D.; Depierreux, M.; Vanhaelen-Fastre, R.; Vanhaelen, M.; Dratwa, M.; Richard, C.; Vandervelde, D.; Verbeelen, D.; et al. Rapidly progressive interstitial renal fibrosis in young women: Association with slimming regimen including Chinese herbs. Lancet 1993, 341, 387-391. [CrossRef]

14. Depierreux, M.; Van Damme, B.; Vanden Houte, K.; Vanherweghem, J.L. Pathologic aspects of a newly described nephropathy related to the prolonged use of Chinese herbs. Am. J. Kidney Dis. 1994, 24, 172-180. [CrossRef]

15. Koh, H.L.; Wang, H.; Zhou, S.; Chan, E.; Woo, S.O. Detection of aristolochic acid I, tetrandrine and fangchinoline in medicinal plants by high performance liquid chromatography and liquid chromatography/mass spectrometry. J. Pharmaceut. Biomed. 2006, 40, 653-661. [CrossRef]

16. Guo, L.; Yue, H.; Cai, Z.W. A novel pre-column fluorescent derivatization method for the sensitive determination of aristolochic acids in medicinal herbs by high-performance liquid chromatography with fluorescence detection. J. Pharmaceut. Biomed. 2010, 53, 37-42. [CrossRef]

17. Wang, Y.A.; Chan, W. Determination of aristolochic acids by high-performance liquid chromatography with fluorescence detection. J. Agric. Food Chem. 2014, 62, 5859-5864. [CrossRef]

18. Wang, X.R.; Wang, Y.Y.; Wang, Y.D.; Chen, Q.; Liu, X. Nanobody-alkaline phosphatase fusion-mediated phosphate-triggered fluorescence immunoassay for ochratoxin a detection. Spectrochim. Acta A 2020, 226, 117617. [CrossRef]

19. Inui, H.; Takeuchi, T.; Uesugi, A.; Doi, F.; Takai, M.; Nishi, K.; Miyake, S.; Ohkawa, H. Enzyme-linked immunosorbent assay with monoclonal and single-chain variable fragment antibodies Selective to Coplanar Polychlorinated Biphenyls. J. Agric. Food Chem. 2012, 60, 1605-1612. [CrossRef]

20. Zhou, J.J.; Ren, M.S.; Wang, W.J.; Huang, L.; Lu, Z.C.; Song, Z.Y.; Foda, M.F.; Zhao, L.; Han, H.Y. Pomegranate-inspired silica nanotags enable sensitive dual-modal detection of rabies virus nucleoprotein. Anal. Chem. 2020, 92, 8802-8809. [CrossRef]

21. Liu, Y.Z.; Zhao, G.X.; Wang, P.; Liu, J.; Zhang, H.C.; Wang, J.P. Production of the broad specific monoclonal antibody against sarafloxacin for rapid immunoscreening of 12 fluoroquinolones in meat. J. Environ. Sci. Heal. B 2013, 48, 139-146. [CrossRef]

22. Li, Y.; Liu, L.Q.; Kuang, H.; Xu, C.L. Preparing monoclonal antibodies and developing immunochromatographic strips for paraquat determination in water. Food Chem. 2020, 311, 125897.1-125897.9. [CrossRef]

23. Wu, Y.P.; Wang, J.; Zhou, Y.; Qi, Y.; Ma, L.C.; Wang, X.N.; Tao, X.Q. Quantitative determination of nitrofurazone metabolites in animal-derived foods based on a background fluorescence quenching immunochromatographic Assay. Foods 2021, $10,1668$. [CrossRef]

24. Chen, X.R.; Miao, X.T.; Ma, T.T.; Leng, Y.K.; Hao, L.W.; Duan, H.; Yuan, J.; Li, Y.; Huang, X.L.; Xiong, Y.H. Gold nanobeads with enhanced absorbance for improved sensitivity in competitive lateral flow immunoassays. Foods 2021, 10, 1488. [CrossRef]

25. Tao, X.Q.; Zhou, S.; Yuan, X.M.; Li, H.J. Determination of chloramphenicol in milk by ten chemiluminescent immunoassays: Influence of assay format applied. Anal. Methods 2016, 8, 4445-4451. [CrossRef] 
26. Xu, L.; Suo, X.Y.; Zhang, Q.; Li, X.P.; Chen, C.; Zhang, X.Y. ELISA and chemiluminescent enzyme immunoassay for sensitive and specific determination of lead (II) in Water, Food and Feed Samples. Foods 2020, 9, 305. [CrossRef]

27. Yi, K.Y.; Zhang, X.T.; Zhang, L. Eu ${ }^{3+} @$ metal-organic frameworks encapsulating carbon dots as ratiometric fluorescent probes for rapid recognition of anthrax spore biomarker. Sci. Total Environ. 2020, 743, 140692. [CrossRef]

28. Li, T.X.; Li, Z.; Huang, T.Z.; Tian, L. Carbon quantum dot-based sensors for food safety. Sens. Actuators A Phys. $2021,331,113003$. [CrossRef]

29. Song, P.; Liu, Q.; Zhang, Y.; Liu, W.; Meng, M.; Yin, Y.M.; Xi, R.M. The chemical redox modulated switch-on fluorescence of carbon dots for probing alkaline phosphatase and its application in an immunoassay. RSC Adv. 2018, 8, 162-169. [CrossRef]

30. Ni, P.J.; Xie, J.F.; Chen, C.X.; Jiang, Y.Y.; Lu, Y.Z.; Hu, X. Fluorometric determination of the activity of alkaline phosphatase and its inhibitors based on ascorbic acid-induced aggregation of carbon dots. Microchim. Acta 2019, 202, 186. [CrossRef]

31. Li, G.L.; Fu, H.L.; Chen, X.J.; Gong, P.W.; Chen, G.; Xia, L.; Wang, H.; You, J.M.; Wu, Y.N. Facile and sensitive fluorescence sensing of alkaline phosphatase activity with photoluminescent carbon dots based on inner filter effect. Anal. Chem. 2016, 88, 2720-2726. [CrossRef] [PubMed]

32. Chen, Z.J.; Liu, X.X.; Xiao, Z.L.; Fu, H.J.; Huang, Y.P.; Huang, S.Y.; Shen, Y.D.; He, F.; Yang, X.X.; Hammock, B.; et al. Production of a specific monoclonal antibody for 1-naphthol based on novel hapten strategy and development of an easy-to-use ELISA in urine samples. Ecotox. Environ. Saf. 2020, 196, 110533. [CrossRef] [PubMed]

33. Chen, Z.J.; Zhou, K.; Ha, W.Z.; Chen, P.H.; Fu, H.J.; Shen, Y.D.; Sun, Y.M.; Xu, Z.L. Development of a low-cost, simple, fast and quantitative lateral-flow immunochromatographic assay (ICA) strip for melatonin in health foods. Food Agric. Immunol. 2019, 30, 497-509. [CrossRef] 